\title{
TURBULENT TEMPERATURE FLUCTUATIONS IN THE PLT TOKAMAK PLASMA
}

V. ARUNASALAM, R, CANO, J. C. HOSEA, AND E. MAZZUCATO

\section{PLASMA PHYSICS LABORATORY}

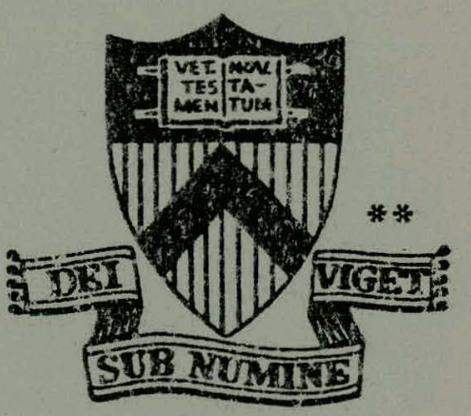

\section{PRINCETON

This work was supported by U. S. Fnergy Research and Development Adninistration Contract EY-76-C-02-3073. Reproduction, trarısiation, pulolication, use anc disposal, in whole or in part, by or for the united states covernment is permitted. 


\section{DISCLAIMER}

This report was prepared as an account of work sponsored by an agency of the United States Government. Neither the United States Government nor any agency Thereof, nor any of their employees, makes any warranty, express or implied, or assumes any legal liability or responsibility for the accuracy, completeness, or usefulness of any information, apparatus, product, or process disclosed, or represents that its use would not infringe privately owned rights. Reference herein to any specific commercial product, process, or service by trade name, trademark, manufacturer, or otherwise does not necessarily constitute or imply its endorsement, recommendation, or favoring by the United States Government or any agency thereof. The views and opinions of authors expressed herein do not necessarily state or reflect those of the United States Government or any agency thereof. 


\section{DISCLAIMER}

Portions of this document may be illegible in electronic image products. Images are produced from the best available original document. 


\section{NOTICE}

This report was prepared as an account of work sponsored by the United states Government. Neither the United States nor the United States Energy Research and Development Administration, nor any of their employees, nor any of their contractors, subcontractors, or their employees, makes any warranty, express or implied, or assumes any legal liability or responsibility for the accuracy, completeness or usefulness of any information, apparatus, product or process disclosed, or represents that its use would not infringe privately owned rights.

$$
\text { Printed in the United States of America. }
$$

Available from

National Technical Information Service

U. S. Department of Commerce 5285 Port Royal Road Springfield, Virginia 22151 Price: Printed Copy \$_*; Microfiche $\$ 3.00$

\section{*Pages}

$$
\begin{gathered}
1-50 \\
51-150 \\
151-325 \\
326-500 \\
501-1000
\end{gathered}
$$

NTIS

Selling Price

$\$ 4.00$

5.45

7.60

10.60

13.60 
Turbulent Temperature Fluctuations in the PLT Tokamak Plasma

V. Arunasalam, R. Cano, J. C. Hosea, and E. Mazzucato

Plasma Physics Laboratory, Princeton University,

Princeton, New Jersey 08540

PPPL-1363

July 1977

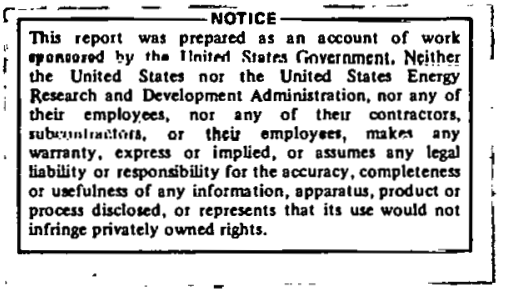


Turbulent Temperature Fluctuations in the PLT Tokamak Plasma*

V. Arunasalam, R. Cano ${ }^{\dagger}$, J. C. Hosea, and E. Mazzucato Plasma Physics Laboratory, Princeton University, Princeton, New Jersey 08540

\section{ABSTRACT}

The first experimental evidence for the existence of turbulent temperature fluctutations in plasmas is presented. The measurements of temperature turbulence were accomplished by a spectral analysis of black-body electron cyclotron emission. The fractional fluctuation in the mean electron energy $F=\left[\left\langle\delta \varepsilon^{2}\right\rangle /\langle\varepsilon\rangle^{2}\right]^{1 / 2}$ $=\left[\left\langle\delta \mathrm{T}_{\mathrm{e}}^{2}\right\rangle / \mathrm{T}_{\mathrm{e}}^{2}\right]^{1 / 2}$ is about $10 \%$ for typical PLT discharges. The frequency spectrum of the temperature turbulence extends well beyond the electron diamagnetic drift frequency $f_{*}$ and does not show any resemblance to the simultaneously existing turbulent drift wave density fluctuations. 
There have been extensive experimental studies of turbulent density fluctuations (such as those associated with drift waves, ion acoustic waves, electron plasma waves, etc.) in linear and toroidal plasma devices. ${ }^{1}$ The purpose of these studies has been to identify the cause of turbulent density fluctuations and to examine the possible dependence of the observed apparent anomalous particle and energy confinement properties as well as the observod anomalous skin effect and the electrical resistivity of plasmas on the level of turbulence. These anomalous transport and resistive properties of plasmas can be caused not only by. turbulent density fluctuations but also hy turbulont temperalure fluctuations. It is needless to say that a clear understanding of turbulence in toroidal plasmas is of vital importance to and is of considerable current interest in tokamak fusion research. To our knowledge no prior experimental study of turbulent temperature fluctuations in plasmas has been reported in the literature. The apparent reason for the total lack of experimental information on temperature fluctuations in plasmas is due to the fact that the conventional plasma diagnostic techniques (such as the scattering of electromagnetic waves from plasmas, Langmuir probes in low density, low temperature laboratory plasmas, etc.) are capable of measuring only the density fluctuations and are not at all sensitive to temperature fluctuations. In this letter'we wish to present the first experimental evidence for the existence of turbulent temperature fluctuations in plasmas. These measurements of temperature turbulence in the PLT tokamak plasma were accomplished by a spectral analysis of black-body emission near 
the second harmonic of the electron cyclotron frequency ${ }^{2}$ (i.e., $\left.f \approx 2 \mathrm{f}_{\mathrm{ce}}\right)$.

Figure 1 is a schematic block diagram of the experimental arrangement. Black-body microwave emission near the second harmonic of the electron cyclotron frequency $f \approx 2 f$ ce from the PLT tokamak plasma is collected by the receiver horn and is mixed with a fixed amount of reference signal from a local oscillator ( $f \approx 140 \mathrm{GHz}$ ). The resultant radio frequency (r.f.) output is amplified (by an amplifier of bandwidth $\Delta \mathrm{f} \approx 400 \mathrm{MHz}$ ) and is then detected with an r.f. detector. The signal from the output of the detector is both displayed on a scope to provide measurements of the absolute value of the electron temperature $\mathrm{T}_{\mathrm{e}}$, and is Fourier analyzed in the spectrum analyzer so as to make measurements on turbulent temperature fluctuations $\delta T_{e}(f)$. The receiving antenna (a horn-lens combination) is located in the equitorial plane along the major radius $R$ and is oriented to receive extraordinary waves propagating mainly perpendicular to the toroidal magnetic field $\mathrm{B}_{\phi}$. Here $\mathrm{R}=\mathrm{R}_{0}+\mathrm{r}$ where $\mathrm{R}_{\mathrm{O}}=132 \mathrm{~cm}$ is the nominal major radius at the center of the plasma. Since in tokamaks $\mathrm{B}_{\phi} \propto \mathrm{R}^{-1}$, the emitting black-body second harmonic layer $f \approx 2 f_{c e}(\mathrm{l})$ can be placed at the desired $R$ or $r$ by shoosing the appropriate magnetic field level $\mathrm{B}_{\phi}\left(\mathrm{R}_{\mathrm{O}}\right)$ for the fixed receiver frequency $\mathrm{f} \approx 140 \mathrm{GHz}$. Thus we can measure the radial distribution of the level of temperature turbulence $\delta T_{e}(f, r)$ in the plasma. The spatial resolution is set by the receiver bandwidth $\Delta f \approx 400 \mathrm{MHz}$ which gives a layer thickness $\Delta R \approx 0.4 \mathrm{~cm}$ and by the lobe width $\Delta \theta \approx \pm 2^{\circ}$ of the 
horn-lens combination located at $r \approx 50 \mathrm{~cm}$ which gives a spot diameter $d \approx 3 \mathrm{~cm}$. Consequently, our method is sensitive to fluctuations with correlation lengths $L>d$.

From hot plasma theory, ${ }^{3}$ one can show that for electromagnetic waves of $f \approx 2 f_{\text {ce }}$ propagating perpendicularly to $\mathrm{B}_{\phi}$ "(i.e., $\theta \approx \pi / 2$ ) the imaginary part of the 'wave number $\mathrm{k}_{\mathrm{I}} \approx\left(4 \pi^{2} \mathrm{f}_{\mathrm{pe}}^{2} \mathrm{kT} \mathrm{e}^{/ 2 \mathrm{mc} c^{3}}\right)[(6-\mathrm{b}) /(6-2 \mathrm{~b})]^{2} \delta\left(f-2 \mathrm{f}_{\mathrm{ce}}\right)$ where

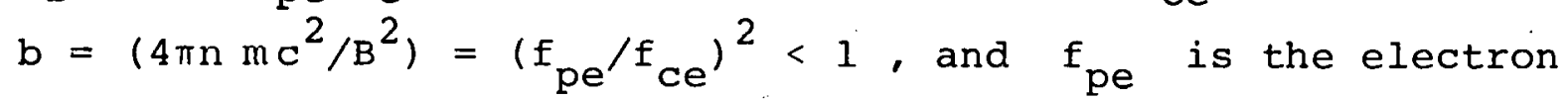
plasma frequency. The total pptical depth for absorption of the radiation in a geometrical path length $\ell$ is given by $\tau=\int_{0}^{l} \mathrm{~d} l 2 \mathrm{k}_{I}$. For our receiver system, the nutput signalo on the scope are proportional to the emitted power $P$. That is,

$$
P=k T e^{(R)} \Delta f[1-\exp (-\tau)],
$$

since the receiving antenna is approximately one dimensional. The output signal on the spectrum analyzer is then propoilional. to $\delta \mathrm{P}$ which in turn is proportional to $\delta \mathrm{T}_{\mathrm{e}}$ if $\tau>1$. (i.e., when the emitting second harmonic layer is optically thick). In a tokamak : $\mathrm{f}_{\mathrm{ce}} \propto \mathrm{R}^{-1}$, and for $\mathrm{f} \approx 2 \mathrm{f}_{\mathrm{Ce}}, \tau \approx\left(\mathrm{R} / 2 \mathrm{f}_{\mathrm{ce}}\right)$ $\left(4 \pi^{2} \mathrm{f}_{\mathrm{pe}}^{2} \mathrm{kT}^{\mathrm{kT}} \mathrm{e}^{/ \mathrm{m} \mathrm{c}}\right)\left[((6-\mathrm{b}) /(6-2 \mathrm{~b})]^{2}\right.$. For $\mathrm{b}<1, \mathrm{t} \propto \mathrm{nT}$ e and thus $(\delta \mathrm{P} / \mathrm{P}) \approx\left(\delta \mathrm{T}_{\mathrm{e}} / \mathrm{T}_{\mathrm{e}}\right)+\tau(\exp \tau-1)^{-1}\left[\left(\delta \mathrm{T}_{\mathrm{e}} / \mathrm{T}_{\mathrm{e}}\right)+(\delta \mathrm{n} / \mathrm{n})\right]$. Hence, $(\delta \mathrm{P} / \mathrm{P}) \approx 2\left(\delta \mathrm{T}_{\mathrm{e}} / \mathrm{T}_{\mathrm{e}}\right)+(\delta \mathrm{n} / \mathrm{n})$ for $\tau<<$; and $(\delta \mathrm{P} / \mathrm{P}) \approx\left(\delta \mathrm{T}_{\mathrm{e}} / \mathrm{T}_{\mathrm{e}}\right)$. for $\tau \gg 1$. That is, for a tenuous plasma the fractional fluctuation in the emitted power is a consequence of the fractional fluctuations "in both the temperature and density. But for an optically thick ${ }^{2}$ (i.e., black) plasma $(\delta \mathrm{P} / \mathrm{P}$ ) is determined only by $\left(\delta \mathrm{T}_{\mathrm{e}} / \mathrm{T}_{\mathrm{e}}\right)$. For our plasma conditions $\tau$ varied from the value 
7.3 at $r=0$ (i.e., the plasma center) to the value 1 at $r=30 \mathrm{~cm}$. Our measurements of the absolute value of $P(R)$ in conjunction with the laser Thomson scattering measurements of $\mathrm{T}_{\mathrm{e}}(\mathrm{R})$ show that the $2 \mathrm{f}_{\mathrm{ce}}$-layer is optically thick for $r \leqslant 25 \mathrm{~cm}$. ( $\mathrm{l} \gtrsim 2$ for black-body emission). Furthermore, as we shall see later, our measurements of $(\delta \mathrm{P} / \mathrm{P})$ in conjunction with the 2-mm microwave scattering measurements of $(\delta n / n)$ clearly show that $(\delta P / P) \gg(\delta n / n)$ and the frequency power spectra of $\delta \mathrm{P}$ and $\delta \mathrm{n}$ are quite different. Hence, we believe that our measurements of $(\delta \mathrm{P} / \mathrm{P})$ to be reported in this letter are clearly a consequence of $\left(\delta \mathrm{T}_{\mathrm{e}} / \mathrm{T}_{\mathrm{e}}\right)$ resulting from the existence of turbulent temperature fluctuations in the PLT tokamak plasmas.

In Fig. 2a, we present the temporal evolution of $\mathrm{P}(\mathrm{R} \approx 142 \mathrm{~cm})$ for a typjcal PLT discharge. ${ }^{4}$ The $T_{e}(R, t)$ obtained from this data by using Eq. (1) with $\tau>>1$ is in very good agreement with the corresponding laser Thomson scattering measurements of $T_{e}(R, t)$. In Fig. $2 b$ we show the power spectrum of the turbulent temperature fluctuations at $t \approx 200 \mathrm{msec}$. From the data of Figs. $2 a$ and $2 b$ we find that $(\delta P / P) \approx\left(\delta T_{e} / T_{e}\right) \approx 0.1$. In Fig. 2c we show the corresponding instrumental noise level (i.e., the spectrum in the absence of plasma). The signal to noise ratio is remarkably good. The 2-mm microwave scattering measurements in PLT show the presence of turbulent drift wave density fiuctuations similar to those which were detected in the ATC tokamak. ${ }^{1}$ In Fig. $2 d$ we show the frequency spectrum of the density fluctuations in PLT with a wavelength $\lambda \approx 1.4 \mathrm{~cm}$. It should be noted from Figs. $2 b$ and $2 d$ that the spectrum of the temperature fluctuations is quite different from that of the 
density fluctuations. In particular the spectrum of $\delta T_{e}$. is much broader and extends to much higher frequencies than that of $\delta \mathrm{n}$. Moreover our measurements indicate that $(\delta \mathrm{n} / \mathrm{n})<\left(\delta \mathbf{T}_{\mathrm{e}} / \mathrm{T}_{\mathrm{e}}\right)$.

By changing the toroidal magnetic field ${ }^{B_{\phi}}\left(R_{0}\right)$ from $25 \mathrm{kG}$ to $29 \mathrm{kG}$ it was possible to measure the radial distribution of the level of temperature turbulence in PLT from $r \approx 0 \mathrm{~cm}$ to $r \approx 20 \mathrm{~cm}$. Our measurements indicate that $\left(\delta \mathrm{T}_{\mathrm{e}} / \mathrm{T}_{\mathrm{e}}\right)$ is fairly constant in this radial interval. For values of $r$ ranging from $30 \mathrm{~cm}$ to the edge of the PLT plasma $(i . e ., 40 \mathrm{~cm}), \delta \mathrm{P}$ fluctuations have contributions both from $\delta \mathrm{T}_{\mathrm{e}}$ and $\delta \mathrm{n}$ fluctuations, since $T_{e}$ and $n$ are decroasing towards the plasild enge and in this range $\tau<1$.

It is now physically instructive to pose the following questions: Are these (1) really turbulent temperature fluctuations? (2) thermodynamic equilibrium fluctuations of the photon occupation

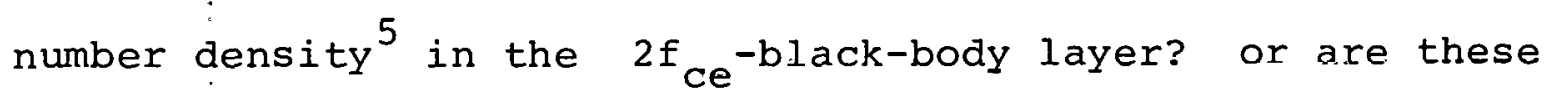
${ }^{S} \mathrm{~T}_{\mathrm{e}}$ Iluctuations due to: $(3)$ second sound ${ }^{6}$ (i.e., energy density waves which in turn yield temperature waves by the equipartition theorem) in the background density wave turbulence such as the drift wave turbulence? (4) stochastic wandering of the magnetic field lines (i.e., magnetic braiding) ${ }^{7}$ due to some background density wave turbulence? (5) local fluctuations in the current density $j(r)$ [since $j(r) \propto \mathrm{T}^{3 / 2}(r)$ ] resulting from a stochastic break up of the magnetic islands ${ }^{7}$ by the background drift wave, drift tearing mode, Alfven wave, etc. turbulence? or (6) Is it a direct consequence of the simultaneously existing density fluctuations due to drift wave turbulence? ${ }^{8}$ and finally (7) Is 
it a new normal mode of an inhomogeneous toroidal plasma corresponding to a temperature wave which has gone unstable? etc. our principal aim in posing these theoretical questions is to stimulate the interest of plasma theoreticians towards the problems of plasma temperature turbulence, since to our knowledge no analysis of this problem exists in the literature.

In order to answer the questions (1), (2), and (6), let us suppose that photons are produced with random phases $\Phi$ from a large number $\mathrm{N}$ of uncorrelated gyrating electrons in the second harmonic black-body layer. Let $\tau_{0}$ be the lifetime of the photon (i.e., the time between the processes of emission and reabsorption). The photon number is proportional to the fieldenergy $W=E_{0}^{2} \exp \left(-t / \tau_{0}\right)\left(\Sigma \exp i \phi_{j}\right)^{*}\left(\Sigma \exp i \phi_{j}\right)$ where $E_{0}$ is the electric field intersity from a single gyrating electron. Then one can show ${ }^{5}$ that the fractional fluctuations in the field energy $\left(\left\langle\delta W^{2}\right\rangle /\langle W\rangle^{2}\right)^{1 / 2}=\left[\left(\left\langle W^{2}\right\rangle-\langle W\rangle^{2}\right) /\langle W\rangle^{2}\right]^{1 / 2} \approx 1$, and $\left\langle\delta W^{2}\right\rangle$ $\propto \exp \left(-2 t / \tau_{0}\right)$. Thus the fractional fluctuations in the field energy is of order unity and the half width of the power spectrum of $\left\langle\delta W^{2}\right\rangle^{1 / 2}$ is $\Delta f_{0} \approx\left(2 \pi \tau_{0}\right)^{-1}$. If we assume that the $2 f_{c e}$-layer still remains a black-body, then $(\delta \mathrm{W} / \mathrm{W}) \approx(\delta \mathrm{P} / \mathrm{P}) \approx\left(\delta \mathrm{T}_{\mathrm{e}} / \mathrm{T}_{\mathrm{e}}\right) \approx 1$. However, at equilibrium one can show ${ }^{5}$ that the fractional fluctuations of the mean electron energy in the grand canonical ensemble is $F=\left[\left\langle\delta \varepsilon^{2}\right\rangle /\langle\varepsilon\rangle^{2}\right]^{1 / 2}=\left[\left\langle\delta T_{e}^{2}\right\rangle / T_{e}^{2}\right]^{1 / 2}=\left[\left(\kappa T_{e}^{2} / U^{2}\right)\left(\partial U / \partial T_{e}\right)_{N}\right.$ $+\left(\left\langle\delta \mathrm{N}^{2}>/ \mathrm{U}^{2}\right)(\partial \mathrm{U} / \partial \mathrm{N})_{\mathrm{T}_{\mathrm{e}}}^{2}\right]^{1 / 2}$, where $\mathrm{U}$ is the internal energy ${ }^{9}$ and at equilibrium $U=N K T_{e} \cdot$ Hence, at equilibrium $F \approx\left(\delta T_{e} / T_{e}\right)$ $\approx 2^{1 / 2}(\delta \mathrm{N} / \mathrm{N}) \approx 2^{1 / 2} \mathrm{~N}^{-1 / 2} \leqslant 10^{-7}$ for our experimental conditions. Since experimentally we find that the $2 f_{c e}$-layer is a black-body, ${ }^{2}$ from the equipartition theorem it follows that $(\delta w / W)$ must remain 
equal to $F$ and that the free fluctuations $\delta W \sim W$ are not allowed. Hence, we beilieve that our measurements are really measurements of turbulent temperature fluctuations and not of thermodynamic equilibrium fluctuations. Finally, we wish to state that the possible causes of this turbulence mentioned in questions (3) to (7) are likely candidates for our measurements.

In conclusion, we have presented the first experimental evidence for the existence of turbulent temperature fluctuations in plasmas. The fractional fluctuation $F=\left(\delta \mathrm{T}_{e} / \mathrm{T}_{e}\right) \approx 10 \%$ for typical PLT discharges. Such large levels of temperature turbulence may be partly responsible for the observed anomalous transport and resistive properties of tokamak plasmas.

We acknowledge the valuable assistance received from the members of the PLT group. We thank Dr. P. K. Kaw for useful discussions and suggestions. 


\section{REFERENCES}

*Work supported by U. S. Energy Research and Development Administration, contract EY-76-C-02-3073.

†Permanent address: Centre d'Etudes Nucleaires, Fontenay-auxRoses, France.

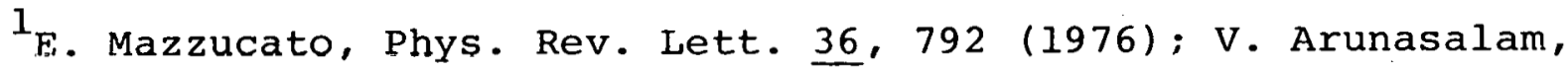
M. Okabayashi, R. J. Hawryluk, and S. Suckewer, Phys. Fluids 20, 95 (1977); V. Arunasalam, M. A. Heald, and J. Sinnis, Phys. Fluids 14, 1194 (1971).

2.A. E. Costley, R. J. Hastie, J. W. M. Paul, and J. Chamberlain, Phys. Rev. Lett. $\underline{33}, 758$ (1974); J. Hosea, and V. Arunasalam, Bull. Am. Phys. Soc. 21, 1159 (1976). For typical discharges in PLT and in TFR, prior experiments clearly show that the $2 \mathrm{f}_{\mathrm{ce}}$-layer is optically thick.

3. H. Stix, The Theory of Plasma Waves (McGraw-Hill, New York, 1962); G. Bekefi, Radiation Processes in a Plasma (Wiley, New York, 1966); V. Arunasalam, E. B. Meservey, M. N. Gurnee, and R. C. Davidson, Phys. Fluids 11, 1076 (1968).

${ }^{4}$ D. Grove, et al., Plasma Physics and Controlled Nuclear Fusion Research, IAEA, Vienna 1977, Vol. 1, p. 21.

${ }^{5}$ C. Kittel, Elementary statistical Physics (Wiley, New York, 19581.

${ }^{6}$ V. A. Liperovskii, and V. N. Tsytovich, Zh. Tekh, Fiz. $\underline{36}$, 575 (1966) [Sov. Phys.-Tech. Phys. 11, 432 (1966)]; E. A. Kaner, and V. M. Yakovenko, Zh. Eksp. Teor. Fiz. 58, 587 (1970) [Sov. Phys. JETP $\underline{31}, 316$ (1970)]; S. Ichimaru, Phys. Rev. 165. 251 (1968). 
${ }^{7}$ A. B. Rechester, and T:H. Stix, Phys. Rev. Lett. 36,587 (1976); J. M. Finn and P. K. Kaw, Phys. Fluids 20, 72 (1977); R. D. Hazeltine and H. R. Strauss, Phys. Rev. Lett. 37, 102 (1976). ${ }^{8}$ B. Coppi, and E. Mazzucato., Phys. Fluids 14, 134 (1971); S. T. Tsai, F. W. Perkins, and T. H. Stix, Phys. Fluids 13 , 2108 (1970); R. F. Ellis, and R. W. Motley, Phys. Fluids 17 , $582(1974)$.

${ }^{9}$ In nonequilibrium situations $\mathrm{U} \gg \mathrm{NKT}_{\mathrm{e}}$ and the fluctuations are very much:larger than the thermal level. See, for example, M. J. Klein and L. Tisza, Phys. Rev. 76, 1861 (1949). 


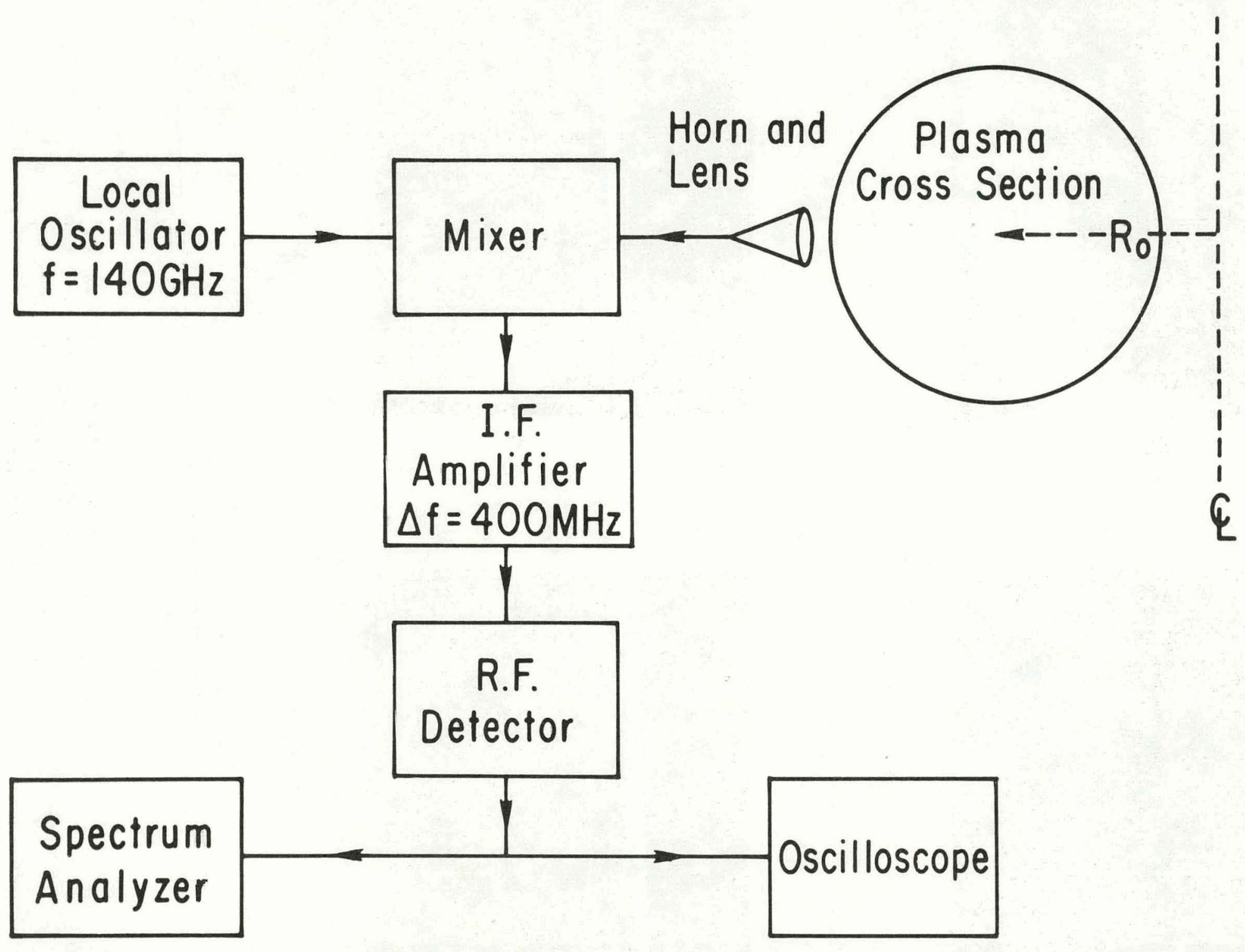



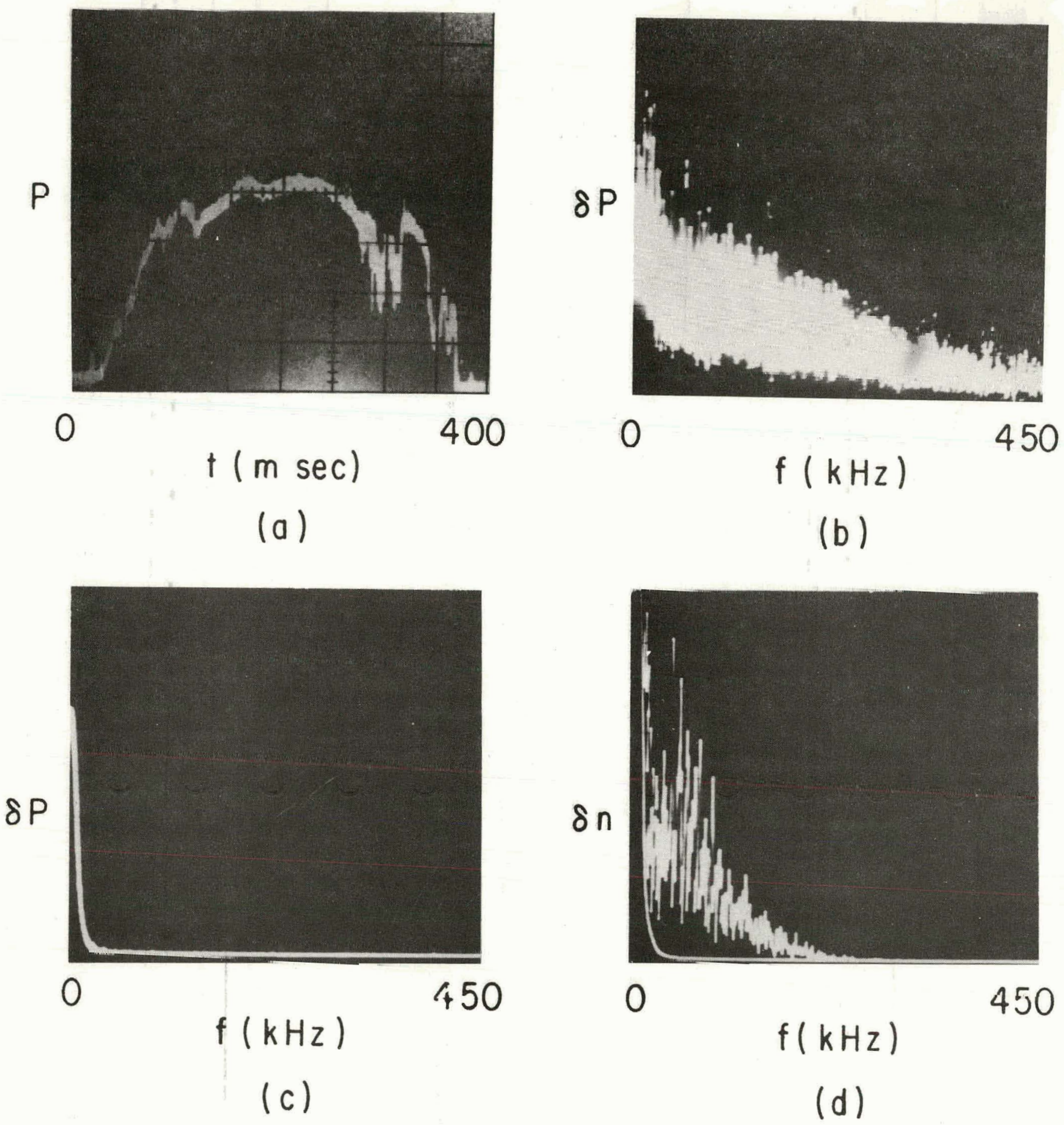

773565

Fig. 2. (a) The temporal evolution of $\mathrm{P}$; (b) The frequency spectrum of $\delta \mathrm{P}$ fluctuations at $t \approx 200 \mathrm{msec}$; (c) The instrumental noise level; (d) The frequency spectrum of the density fluctuations. Conditions are: $\mathrm{B}_{\phi}\left(\mathrm{R}_{0}\right) \approx 27 \mathrm{kG}, \mathrm{T}_{\mathrm{e}}(0) \approx 1.0 \mathrm{keV}, \mathrm{n} \approx 3 \times 10^{13}\left(1-\mathrm{r}^{2}\right)$ $\left.40^{2}\right) \mathrm{cm}^{-3}, f_{*} \approx 50 \mathrm{kHz}$ for $\lambda \approx 1.5 \mathrm{~cm}$. 